\title{
STRONG CONVERGENCE AND CONTROL CONDITION OF MODIFIED HALPERN ITERATIONS IN BANACH SPACES
}

\author{
YONGHONG YAO, RUDONG CHEN, AND HAIYUN ZHOU
}

Received 27 August 2005; Revised 14 February 2006; Accepted 28 February 2006

Let $C$ be a nonempty closed convex subset of a real Banach space $X$ which has a uniformly Gâteaux differentiable norm. Let $T \in \Gamma_{C}$ and $f \in \Pi_{C}$. Assume that $\left\{x_{t}\right\}$ converges strongly to a fixed point $z$ of $T$ as $t \rightarrow 0$, where $x_{t}$ is the unique element of $C$ which satisfies $x_{t}=t f\left(x_{t}\right)+(1-t) T x_{t}$. Let $\left\{\alpha_{n}\right\}$ and $\left\{\beta_{n}\right\}$ be two real sequences in $(0,1)$ which satisfy the following conditions: $\left(\mathrm{C}_{1}\right) \lim _{n \rightarrow \infty} \alpha_{n}=0 ;\left(\mathrm{C}_{2}\right) \sum_{n=0}^{\infty} \alpha_{n}=\infty ;\left(\mathrm{C}_{6}\right) 0<\liminf _{n \rightarrow \infty} \beta_{n} \leq$ $\limsup _{n \rightarrow \infty} \beta_{n}<1$. For arbitrary $x_{0} \in C$, let the sequence $\left\{x_{n}\right\}$ be defined iteratively by $y_{n}=\alpha_{n} f\left(x_{n}\right)+\left(1-\alpha_{n}\right) T x_{n}, n \geq 0, x_{n+1}=\beta_{n} x_{n}+\left(1-\beta_{n}\right) y_{n}, n \geq 0$. Then $\left\{x_{n}\right\}$ converges strongly to a fixed point of $T$.

Copyright (c) 2006 Hindawi Publishing Corporation. All rights reserved.

\section{Introduction}

Let $X$ be a real Banach space, and $C$ a closed convex subset of $X$. Recall that a self-mapping $f: C \rightarrow C$ is a contraction on $C$ if there exists a constant $\alpha \in(0,1)$ such that

$$
\|f(x)-f(y)\| \leq \alpha\|x-y\|, \quad x, y \in C
$$

We use $\Pi_{C}$ to denote the collection of all contractions on $C$. That is, $\Pi_{C}=\{f: C \rightarrow$ $C$ a contraction . Note that each $f \in \Pi_{C}$ has a unique fixed point in $C$.

Let now $T: C \rightarrow C$ be a nonexpansive mapping; namely,

$$
\|T x-T y\| \leq\|x-y\| \quad \forall x, y \in C .
$$

We use $F(T)$ to denote the set of fixed points of $T$.

Construction of fixed points of nonexpansive mappings is an important subject in the theory of nonexpansive mappings and its applications in a number of applied areas, in particular, in image recovery and signal processing (see $[1,2,6])$. However, the sequence $\left\{T^{n} x\right\}$ of iterates of the mapping $T$ at a point $x \in C$ may, in general, not behave well. This means that it may not converge (even in the weak topology). 
One way to overcome this difficulty is to use Mann's iteration method that produces a sequence $\left\{x_{n}\right\}$ via the recursive manner:

$$
x_{n+1}=\alpha_{n} x_{n}+\left(1-\alpha_{n}\right) T x_{n}, \quad n \geq 0,
$$

where the initial guess $x_{0} \in C$ is chosen arbitrarily. For example, Reich [7] proved that if $X$ is a uniformly convex Banach space with a Frechet differentiable norm and if $\left\{\alpha_{n}\right\}$ is chosen such that $\sum_{n=1}^{\infty} \alpha_{n}\left(1-\alpha_{n}\right)=\infty$, then the sequence $\left\{x_{n}\right\}$ defined by (1.3) converges weakly to a fixed point of $T$. However, this scheme has only weak convergence even in a Hilbert space [3].

Some attempts to construct iteration method so that strong convergence is guaranteed have recently been made.

For a sequence $\left\{\alpha_{n}\right\}$ of real numbers in $[0,1]$ and an arbitrary $u \in C$, let the sequence $\left\{x_{n}\right\}$ in $C$ be iteratively defined by $x_{0} \in C$,

$$
x_{n+1}=\alpha_{n} u+\left(1-\alpha_{n}\right) T x_{n} .
$$

The iterative method (1.4) is now referred to as the Halpern iterative method in the light of [4]. He proved the weak convergence of $\left\{x_{n}\right\}$ to a fixed point of $T$ where $\alpha_{n}=n^{-a}$, $a \in(0,1)$.

In 1977, Lions [5] improved the result of Halpern, by proving strong convergence of $\left\{x_{n}\right\}$ to a fixed point of $T$ where the real sequence $\left\{\alpha_{n}\right\}$ satisfies the following conditions:

$\left(\mathrm{C}_{1}\right) \lim _{n \rightarrow \infty} \alpha_{n}=0$;

$\left(\mathrm{C}_{2}\right) \sum_{n=0}^{\infty} \alpha_{n}=\infty$;

$\left(\mathrm{C}_{3}\right) \lim _{n \rightarrow \infty}\left(\alpha_{n}-\alpha_{n-1}\right) / \alpha_{n}^{2}=0$.

It was observed that Lions' conditions on the real sequence $\left\{\alpha_{n}\right\}$ excluded the canonical choice $\alpha_{n}=1 /(n+1)$. This was overcome in 1992 by Wittmann [10]. He proved the following theorem.

Theorem 1.1. Let $H$ be a Hilbert space, let $C$ be a nonempty closed and convex subset of $H$ and $T \in \Gamma_{C}$. Let $\left\{\alpha_{n}\right\}$ be a sequence in $[0,1]$ fulfilling $\left(\mathrm{C}_{1}\right),\left(\mathrm{C}_{2}\right)$, and

$\left(\mathrm{C}_{4}\right) \sum_{n=0}^{\infty}\left|\alpha_{n+1}-\alpha_{n}\right|<\infty$.

For arbitrary initial value $x_{0}=u \in C$, define iteratively the sequence $\left\{x_{n}\right\}$ as in (1.4). Then the sequence $\left\{x_{n}\right\}$ converges strongly to the element of $F(T)$ which is nearest to $u$.

At this point, we have to remark that the result of Wittmann is basic and important. Reich [8] extended the Wittmann's result to uniformly smooth Banach spaces which have weakly sequentially continuous duality maps. In 2002, Xu [11] improved Lions' result as follows.

Theorem 1.2. Let $X$ be a uniformly smooth real Banach space, let $C$ be a closed convex subset of $X$, and $T \in \Gamma_{C}$. Let $u, x_{0} \in C$ be given. Assume that $\left\{\alpha_{n}\right\} \subset[0,1]$ satisfies the conditions $\left(\mathrm{C}_{1}\right),\left(\mathrm{C}_{2}\right)$ and,

$\left(\mathrm{C}_{5}\right) \lim _{n \rightarrow \infty}\left(\alpha_{n}-\alpha_{n-1}\right) / \alpha_{n}=0$.

Then the sequence $\left\{x_{n}\right\}$ defined by (1.4) converges strongly to a fixed point of T. 
He showed that condition $\left(\mathrm{C}_{3}\right)$ of Lions and condition $\left(\mathrm{C}_{5}\right)$ are not comparable. $\mathrm{Xu}$ also remarked that Halpern observed that conditions $\left(\mathrm{C}_{1}\right)$ and $\left(\mathrm{C}_{2}\right)$ are necessary for the strong convergence of algorithm (1.4) for all nonexpansive mappings.

Remark 1.3. We note that Theorem 1.2 weakened the condition $\left(\mathrm{C}_{3}\right)$ by removing the square in the denominator so that the canonical choice of $\alpha_{n}=1 /(n+1)$ is possible. On the other hand, $\mathrm{Xu}$ proved the strong convergence of the scheme in the framework of real uniformly smooth Banach spaces.

It is our purpose in this paper to propose a modification of Halpern's iteration method inspired by the ideas in [11]. Our modified Halpern's iteration scheme is defined as follows.

Let $C$ be a closed convex subset of a Banach space and $T \in \Gamma_{C}$ and $f \in \Pi_{C}$. Define $\left\{x_{n}\right\}$ in the following way:

$$
\begin{gathered}
y_{n}=\alpha_{n} f\left(x_{n}\right)+\left(1-\alpha_{n}\right) T x_{n}, \quad n \geq 0, \\
x_{n+1}=\beta_{n} x_{n}+\left(1-\beta_{n}\right) y_{n}, \quad n \geq 0,
\end{gathered}
$$

where $\left\{\alpha_{n}\right\}$ and $\left\{\beta_{n}\right\}$ are two sequences in $(0,1)$. We prove, under certain appropriate assumptions on the sequences $\left\{\alpha_{n}\right\}$ and $\left\{\beta_{n}\right\}$, that $\left\{x_{n}\right\}$ converges to a fixed point of $T$.

\section{Preliminaries and lemmas}

Let $X$ be a real Banach space. Recall that the (normalized) duality map from $X$ into $X^{*}$, the dual space of $X$, is given by

$$
J(x)=\left\{x^{*} \in X^{*}:\left\langle x, x^{*}\right\rangle=\|x\|^{2}=\left\|x^{*}\right\|^{2}\right\}, \quad x \in X .
$$

Let $S=\{x \in X:\|x\|=1\}$ denote the unit sphere of $X . X$ is said to have a Gâteaux differentiable norm if the limit

$$
\lim _{t \rightarrow 0} \frac{\|x+t y\|-\|x\|}{t}
$$

exists for each $x, y \in X$, and $X$ is said to have a uniformly Gâteaux differentiable norm if for each $y \in S$, the limit is attained uniformly for $x \in S$. Let $X$ be a normed space with $\operatorname{dim} X \geq 2$. The modulus of smoothness of $X$ is the function $\rho_{X}:[0, \infty) \rightarrow[0, \infty)$ defined by

$$
\rho_{X}(\tau)=\sup \left\{\frac{\|x+y\|+\|x-y\|}{2}-1:\|x\|=1,\|y\|=\tau\right\} .
$$

The space $X$ is called uniformly smooth if and only if $\lim _{t \rightarrow 0+} \rho_{X}(t) / t=0$.

Now, we introduce several lemmas for our main results in this paper.

The first lemma is a very well-known (subdifferential) inequality.

Lemma 2.1. Let $X$ be a real Banach space and $J$ the normalized duality map on $X$. Then for any given $x, y \in X$, the following inequality holds:

$$
\|x+y\|^{2} \leq\|x\|^{2}+2\langle y, j(x+y)\rangle, \quad \forall j(x+y) \in J(x+y) .
$$


4 Strong convergence and control condition

Lemma 2.2 [9]. Let $\left\{x_{n}\right\}$ and $\left\{y_{n}\right\}$ be bounded sequences in a Banach space $X$ and let $\left\{\beta_{n}\right\}$ be a sequence in $[0,1]$ which satisfies the following condition:

$\left(\mathrm{C}_{6}\right) 0<\liminf _{n \rightarrow \infty} \beta_{n} \leq \limsup _{n \rightarrow \infty} \beta_{n}<1$.

Suppose

$$
\begin{gathered}
x_{n+1}=\beta_{n} x_{n}+\left(1-\beta_{n}\right) y_{n}, \quad n \geq 0, \\
\limsup _{n \rightarrow \infty}\left(\left\|y_{n+1}-y_{n}\right\|-\left\|x_{n+1}-x_{n}\right\|\right) \leq 0 .
\end{gathered}
$$

Then $\lim _{n \rightarrow \infty}\left\|y_{n}-x_{n}\right\|=0$.

Lemma 2.3 [12]. Assume $\left\{a_{n}\right\}$ is a sequence of nonnegative real numbers such that

$$
a_{n+1} \leq\left(1-\gamma_{n}\right) a_{n}+\delta_{n}, \quad n \geq 0,
$$

where $\left\{\gamma_{n}\right\}$ is a sequence in $(0,1)$ and $\left\{\delta_{n}\right\}$ is a sequence in $R$ such that

$\left(\mathrm{C}_{7}\right) \sum_{n=0}^{\infty} \gamma_{n}=\infty$;

$\left(\mathrm{C}_{8}\right) \limsup _{n \rightarrow \infty} \delta_{n} / \gamma_{n} \leq 0$ or $\sum_{n=0}^{\infty}\left|\delta_{n}\right|<\infty$.

Then $\lim _{n \rightarrow \infty} a_{n}=0$.

Lemma 2.4 [13]. Let $X$ be a uniformly smooth Banach space, $C$ a closed convex subset of $X$. $T: C \rightarrow C$ a nonexpansive mapping with $F(T) \neq \varnothing$, and $f \in \Pi_{C}$. Then $\left\{x_{t}\right\}$ defined by

$$
x_{t}=t f\left(x_{t}\right)+(1-t) T x_{t}
$$

converges strongly to a point in $F(T)$.

\section{Main results}

Theorem 3.1. Let $C$ be a nonempty closed convex subset of a real Banach space $X$ which has a uniformly Gâteaux differentiable norm. Let $T \in \Gamma_{C}$ and $f \in \Pi_{C}$. Assume that $\left\{x_{t}\right\}$ converges strongly to a fixed point $z$ of $T$ as $t \rightarrow 0$, where $x_{t}$ is the unique element of $C$ which satisfies $x_{t}=t f\left(x_{t}\right)+(1-t) T x_{t}$. Let $\left\{\alpha_{n}\right\}$ and $\left\{\beta_{n}\right\}$ be two real sequences in $(0,1)$ which satisfy the conditions $\left(C_{1}\right),\left(C_{2}\right)$, and $\left(C_{6}\right)$.

For arbitrary $x_{0} \in C$, define iteratively the sequence $\left\{x_{n}\right\}$ as in (1.5). Then the sequence $\left\{x_{n}\right\}$ converges strongly to a fixed point of $T$.

Proof. First, we observe that $\left\{x_{n}\right\}$ is bounded.

Indeed, if we take a fixed point $p$ of $T$, note that

$$
\begin{aligned}
\left\|x_{n+1}-p\right\| \leq & \beta_{n}\left\|x_{n}-p\right\|+\left(1-\beta_{n}\right)\left\|y_{n}-p\right\| \\
\leq & {\left[\beta_{n}+\left(1-\beta_{n}\right)\left(1-\alpha_{n}\right)\right]\left\|x_{n}-p\right\|+\left(1-\beta_{n}\right) \alpha_{n}\left\|f\left(x_{n}\right)-f(p)\right\| } \\
& +\left(1-\beta_{n}\right) \alpha_{n}\|f(p)-p\| \\
\leq & {\left[1-(1-\alpha) \alpha_{n}+(1-\alpha) \alpha_{n} \beta_{n}\right]\left\|x_{n}-p\right\|+\left(1-\beta_{n}\right) \alpha_{n}\|f(p)-p\| } \\
\leq & \max \left\{\left\|x_{n}-p\right\|, \frac{\|f(p)-p\|}{1-\alpha}\right\} .
\end{aligned}
$$


Now, an induction yields

$$
\left\|x_{n}-p\right\| \leq \max \left\{\left\|x_{0}-p\right\|, \frac{\|f(p)-p\|}{1-\alpha}\right\} .
$$

Hence, $\left\{x_{n}\right\}$ is bounded, so are $\left\{T x_{n}\right\},\left\{y_{n}\right\}$, and $\left\{f\left(x_{n}\right)\right\}$.

Observe that

$$
\begin{aligned}
y_{n+1}-y_{n}= & \alpha_{n+1} f\left(x_{n+1}\right)+\left(1-\alpha_{n+1}\right) T x_{n+1}-\alpha_{n} f\left(x_{n}\right)-\left(1-\alpha_{n}\right) T x_{n} \\
= & \left(\alpha_{n+1}-\alpha_{n}\right) f\left(x_{n+1}\right)+\alpha_{n}\left(f\left(x_{n+1}\right)-f\left(x_{n}\right)\right) \\
& +\left(1-\alpha_{n+1}\right)\left(T x_{n+1}-T x_{n}\right)+\left(\alpha_{n}-\alpha_{n+1}\right) T x_{n} .
\end{aligned}
$$

It follows from (3.3) that

$$
\left\|y_{n+1}-y_{n}\right\|-\left\|x_{n+1}-x_{n}\right\| \leq\left|\alpha_{n+1}-\alpha_{n}\right|\left(\left\|f\left(x_{n+1}\right)\right\|+\left\|T x_{n}\right\|\right)+\alpha_{n}\left\|f\left(x_{n+1}\right)-f\left(x_{n}\right)\right\| .
$$

Since $\left\{f\left(x_{n}\right)\right\},\left\{T x_{n}\right\}$ are bounded, we obtain that

$$
\limsup _{n \rightarrow \infty}\left(\left\|y_{n+1}-y_{n}\right\|-\left\|x_{n+1}-x_{n}\right\|\right) \leq 0
$$

Hence, by Lemma 2.2, we have

$$
\lim _{n \rightarrow \infty}\left\|y_{n}-x_{n}\right\|=0
$$

Observe also that

$$
y_{n}-x_{n}=\alpha_{n}\left(f\left(x_{n}\right)-x_{n}\right)+\left(1-\alpha_{n}\right)\left(T x_{n}-x_{n}\right) .
$$

It follows from $\left(\mathrm{C}_{1}\right),(3.6)$, and (3.7) that

$$
\lim _{n \rightarrow \infty}\left\|x_{n}-T x_{n}\right\|=0 \text {. }
$$

We next show that

$$
\limsup _{n \rightarrow \infty}\left\langle f(z)-z, j\left(x_{n}-z\right)\right\rangle \leq 0 .
$$

Let $x_{t}$ be the unique fixed point of the contraction mapping $z_{t}$ given by

$$
z_{t} x=t f(x)+(1-t) T x
$$

Then

$$
x_{t}-x_{n}=t\left(f\left(x_{t}\right)-x_{n}\right)+(1-t)\left(T x_{t}-x_{n}\right) .
$$


We apply Lemma 2.1 to get

$$
\begin{aligned}
\left\|x_{t}-x_{n}\right\|^{2} \leq & (1-t)^{2}\left\|T x_{t}-x_{n}\right\|^{2}+2 t\left\langle f\left(x_{t}\right)-x_{n}, j\left(x_{t}-x_{n}\right)\right\rangle \\
\leq & (1-t)^{2}\left(\left\|T x_{t}-T x_{n}\right\|+\left\|T x_{n}-x_{n}\right\|\right)^{2} \\
& +2 t\left\langle f\left(x_{t}\right)-x_{t}, j\left(x_{t}-x_{n}\right)\right\rangle+2 t\left\|x_{t}-x_{n}\right\|^{2} \\
\leq & (1-t)^{2}\left\|x_{t}-x_{n}\right\|^{2}+a_{n}(t)+2 t\left\|x_{t}-x_{n}\right\|^{2}+2 t\left\langle f\left(x_{t}\right)-x_{t}, j\left(x_{t}-x_{n}\right)\right\rangle,
\end{aligned}
$$

where

$$
a_{n}(t)=\left\|T x_{n}-x_{n}\right\|\left(2\left\|x_{t}-x_{n}\right\|+\left\|T x_{n}-x_{n}\right\|\right) \longrightarrow 0 \quad \text { as } n \longrightarrow \infty .
$$

The last inequality (3.12) implies

$$
\left\langle x_{t}-f\left(x_{t}\right), j\left(x_{t}-x_{n}\right)\right\rangle \leq \frac{t}{2}\left\|x_{t}-x_{n}\right\|^{2}+\frac{1}{2 t} a_{n}(t) .
$$

It follows that

$$
\limsup _{n \rightarrow \infty}\left\langle x_{t}-f\left(x_{t}\right), j\left(x_{t}-x_{n}\right)\right\rangle \leq \frac{t}{2} M_{1}^{2}
$$

where $M_{1}>0$ is a constant such that $M_{1} \geq\left\|x_{t}-x_{n}\right\|$ for all $t \in(0,1)$ and $n \geq 1$.

Letting $t \rightarrow 0$ in (3.15) and noting (3.13) yields

$$
\underset{t \rightarrow 0}{\limsup } \limsup _{n \rightarrow \infty}\left\langle x_{t}-f\left(x_{t}\right), j\left(x_{t}-x_{n}\right)\right\rangle \leq 0
$$

Moreover, we have that

$$
\begin{aligned}
&\left\langle z-f(z), j\left(z-x_{n}\right)\right\rangle \\
&=\left\langle z-f(z), j\left(z-x_{n}\right)\right\rangle-\left\langle z-f(z), j\left(x_{t}-x_{n}\right)\right\rangle \\
&+\left\langle z-f(z), j\left(x_{t}-x_{n}\right)\right\rangle-\left\langle x_{t}-f(z), j\left(x_{t}-x_{n}\right)\right\rangle \\
&+\left\langle x_{t}-f(z), j\left(x_{t}-x_{n}\right)\right\rangle-\left\langle x_{t}-f\left(x_{t}\right), j\left(x_{t}-x_{n}\right)\right\rangle \\
&+\left\langle x_{t}-f\left(x_{t}\right), j\left(x_{t}-x_{n}\right)\right\rangle \\
&=\left\langle z-f(z), j\left(z-x_{n}\right)-j\left(x_{t}-x_{n}\right)\right\rangle \\
&+\left\langle z-x_{t}, j\left(x_{t}-x_{n}\right)\right\rangle+\left\langle f\left(x_{t}\right)-f(z), j\left(x_{t}-x_{n}\right)\right\rangle \\
&+\left\langle x_{t}-f\left(x_{t}\right), j\left(x_{t}-x_{n}\right)\right\rangle .
\end{aligned}
$$


Then, we obtain

$$
\begin{aligned}
\limsup _{n \rightarrow \infty} & \left\langle z-f(z), j\left(z-x_{n}\right)\right\rangle \\
\leq & \sup _{n \in N}\left\langle z-f(z), j\left(z-x_{n}\right)-j\left(x_{t}-x_{n}\right)\right\rangle+\left\|z-x_{t}\right\| \limsup _{n \rightarrow \infty}\left\|x_{t}-x_{n}\right\| \\
& +\left\|f\left(x_{t}\right)-f(z)\right\| \limsup _{n \rightarrow \infty}\left\|x_{t}-x_{n}\right\|+\limsup _{n \rightarrow \infty}\left\langle x_{t}-f\left(x_{t}\right), j\left(x_{t}-x_{n}\right)\right\rangle \\
\leq & \sup _{n \in N}\left\langle z-f(z), j\left(z-x_{n}\right)-j\left(x_{t}-x_{n}\right)\right\rangle \\
& +(1+\alpha)\left\|z-x_{t}\right\| \limsup _{n \rightarrow \infty}\left\|x_{t}-x_{n}\right\|+\limsup _{n \rightarrow \infty}\left\langle x_{t}-f\left(x_{t}\right), j\left(x_{t}-x_{n}\right)\right\rangle .
\end{aligned}
$$

By hypothesis that $x_{t} \rightarrow z \in F(T)$ as $t \rightarrow 0$ (see Lemma 2.4) and that $j$ is norm-to-weak* uniformly continuous on bounded subset of $C$, we obtain

$$
\limsup _{t \rightarrow 0}\left\langle z-f(z), j\left(z-x_{n}\right)-j\left(x_{t}-x_{n}\right)\right\rangle=0 .
$$

Therefore, we have

$$
\begin{aligned}
\limsup _{n \rightarrow \infty}\left\langle z-f(z), j\left(z-x_{n}\right)\right\rangle & =\limsup _{t \rightarrow 0} \limsup _{n \rightarrow \infty}\left\langle z-f(z), j\left(z-x_{n}\right)\right\rangle \\
& \leq \limsup _{t \rightarrow 0} \limsup _{n \rightarrow \infty}\left\langle x_{t}-f\left(x_{t}\right), j\left(x_{t}-x_{n}\right)\right\rangle \\
& \leq 0 .
\end{aligned}
$$

Finally, we show that $x_{n} \rightarrow z$ as $n \rightarrow \infty$.

Write

$$
\begin{aligned}
x_{n+1}-z & =\beta_{n}\left(x_{n}-z\right)+\left(1-\beta_{n}\right)\left(y_{n}-z\right) \\
& =\beta_{n}\left(x_{n}-z\right)+\left(1-\beta_{n}\right)\left(1-\alpha_{n}\right)\left(T x_{n}-z\right)+\left(1-\beta_{n}\right) \alpha_{n}\left(f\left(x_{n}\right)-z\right),
\end{aligned}
$$

and apply Lemma 2.1 to get

$$
\begin{aligned}
\left\|x_{n+1}-z\right\|^{2} \leq & \left\|\beta_{n}\left(x_{n}-z\right)+\left(1-\beta_{n}\right)\left(1-\alpha_{n}\right)\left(T x_{n}-z\right)\right\|^{2} \\
& +2\left(1-\beta_{n}\right) \alpha_{n}\left\langle f\left(x_{n}\right)-z, j\left(x_{n+1}-z\right)\right\rangle \\
\leq & {\left[\beta_{n}\left\|x_{n}-z\right\|+\left(1-\beta_{n}\right)\left(1-\alpha_{n}\right)\left\|x_{n}-z\right\|\right]^{2} } \\
& +2\left(1-\beta_{n}\right) \alpha_{n}\left\langle f\left(x_{n}\right)-f(z), j\left(x_{n+1}-z\right)\right\rangle \\
& +2\left(1-\beta_{n}\right) \alpha_{n}\left\langle f(z)-z, j\left(x_{n+1}-z\right)\right\rangle \\
\leq & \left(1-\alpha_{n}+\alpha_{n} \beta_{n}\right)^{2}\left\|x_{n}-z\right\|^{2} \\
& +\alpha\left(1-\beta_{n}\right) \alpha_{n}\left(\left\|x_{n}-z\right\|^{2}+\left\|x_{n+1}-z\right\|^{2}\right) \\
& +2\left(1-\beta_{n}\right) \alpha_{n}\left\langle f(z)-z, j\left(x_{n+1}-z\right)\right\rangle .
\end{aligned}
$$


8 Strong convergence and control condition

It then follows that

$$
\begin{aligned}
\left\|x_{n+1}-z\right\|^{2} \leq & \frac{1-(2-\alpha)\left(1-\beta_{n}\right) \alpha_{n}+\left(1-\beta_{n}\right)^{2} \alpha_{n}^{2}}{1-\alpha\left(1-\beta_{n}\right) \alpha_{n}}\left\|x_{n}-z\right\|^{2} \\
& +\frac{2\left(1-\beta_{n}\right) \alpha_{n}}{1-\alpha\left(1-\beta_{n}\right) \alpha_{n}}\left\langle f(z)-z, j\left(x_{n+1}-z\right)\right\rangle \\
= & \left(1-\frac{2(1-\alpha)\left(1-\beta_{n}\right) \alpha_{n}}{1-\alpha\left(1-\beta_{n}\right) \alpha_{n}}\right)\left\|x_{n}-z\right\|^{2} \\
& +\frac{2\left(1-\beta_{n}\right) \alpha_{n}}{1-\alpha\left(1-\beta_{n}\right) \alpha_{n}}\left\langle f(z)-z, j\left(x_{n+1}-z\right)\right\rangle \\
& +\frac{\left(1-\beta_{n}\right)^{2} \alpha_{n}^{2}}{1-\alpha\left(1-\beta_{n}\right) \alpha_{n}}\left\|x_{n}-z\right\|^{2}
\end{aligned}
$$

that is,

$$
\begin{aligned}
\left\|x_{n+1}-z\right\|^{2}= & \left(1-\gamma_{n}\right)\left\|x_{n}-z\right\|^{2} \\
& +\gamma_{n}\left[\frac{1}{1-\alpha}\left\langle f(z)-z, j\left(x_{n+1}-z\right)\right\rangle+\frac{\left(1-\beta_{n}\right) \alpha_{n}}{2(1-\alpha)}\left\|x_{n}-z\right\|^{2}\right] \\
\leq & \left(1-\gamma_{n}\right)\left\|x_{n}-z\right\|^{2}+\gamma_{n}\left[\frac{1}{1-\alpha}\left\langle f(z)-z, j\left(x_{n+1}-z\right)\right\rangle+\frac{\left(1-\beta_{n}\right) \alpha_{n}}{2(1-\alpha)} M_{2}\right] \\
= & \left(1-\gamma_{n}\right)\left\|x_{n}-z\right\|^{2}+\delta_{n},
\end{aligned}
$$

where $\gamma_{n}=2(1-\alpha)\left(1-\beta_{n}\right) \alpha_{n} /\left(1-\alpha\left(1-\beta_{n}\right) \alpha_{n}\right), \delta_{n}=\gamma_{n}\left[(1 /(1-\alpha))\left\langle f(z)-z, j\left(x_{n+1}-\right.\right.\right.$ $\left.z)\rangle+\left(\left(1-\beta_{n}\right) \alpha_{n} / 2(1-\alpha)\right) M_{2}\right]$ and $M_{2}>0$ is a constant such that $\left\|x_{n}-z\right\|^{2} \leq M_{2}, n \geq 1$.

It is easily seen that $\gamma_{n} \rightarrow 0$ as $n \rightarrow \infty, \sum_{n=0}^{\infty} \gamma_{n}=\infty$, and

$$
\limsup _{n \rightarrow \infty} \delta_{n} / \gamma_{n}=\limsup _{n \rightarrow \infty}\left[\frac{1}{1-\alpha}\left\langle f(z)-z, j\left(x_{n+1}-z\right)\right\rangle+\frac{\left(1-\beta_{n}\right) \alpha_{n}}{2(1-\alpha)} M_{2}\right] \leq 0
$$

Finally, apply Lemma 2.3 to (3.24) to conclude that $x_{n} \rightarrow z$ as $n \rightarrow \infty$. This completes the proof.

Corollary 3.2. Let $C$ be a nonempty closed convex subset of a real Banach space $X$ which has a uniformly Gâteaux differentiable norm. Let $T \in \Gamma_{C}$. Assume that $\left\{x_{t}\right\}$ converges strongly to a fixed point $z$ of $T$ as $t \rightarrow 0$, where $x_{t}$ is the unique element of $C$ which satisfies $x_{t}=$ $t u+(1-t) T x_{t}$ for arbitrary $u \in C$. Let $\left\{\alpha_{n}\right\}$ and $\left\{\beta_{n}\right\}$ be two real sequences in $(0,1)$ which satisfy the conditions $\left(C_{1}\right),\left(C_{2}\right)$, and $\left(C_{6}\right)$. 
For arbitrary $x_{0} \in C$, let the sequence $\left\{x_{n}\right\}$ be defined iteratively by

$$
\begin{array}{ll}
y_{n}=\alpha_{n} u+\left(1-\alpha_{n}\right) T x_{n}, & n \geq 0, \\
x_{n+1}=\beta_{n} x_{n}+\left(1-\beta_{n}\right) y_{n}, & n \geq 0 .
\end{array}
$$

Then $\left\{x_{n}\right\}$ converges strongly to a fixed point of $T$.

Remark 3.3. We note that every uniformly smooth Banach space has a uniformly Gâteaux differentiable norm and is such that every nonempty closed convex and bounded subset of $X$ has the fixed point property for nonexpansive mappings. Our Corollary 3.2 extend Theorems 1.1 and 1.2 to the more general real Banach spaces with uniformly Gâteaux differentiable norm and at the same time dispense with conditions $\left(\mathrm{C}_{4}\right)$ and $\left(\mathrm{C}_{5}\right)$, respectively.

Theorem 3.4. Let $C$ be a nonempty closed convex subset of a real uniformly smooth Banach space $X$. Let $T \in \Gamma_{C}$ and $f \in \Pi_{C}$. Let $\left\{\alpha_{n}\right\}$ and $\left\{\beta_{n}\right\}$ be two real sequences in $(0,1)$ which satisfy the conditions $\left(C_{1}\right),\left(C_{2}\right)$, and $\left(C_{6}\right)$. For arbitrary $x_{0} \in C$, define iteratively the sequence $\left\{x_{n}\right\}$ as in (1.5). Then the sequence $\left\{x_{n}\right\}$ converges strongly to a fixed point of $T$.

\section{Acknowledgment}

The authors thank the referee for his/her comments and suggestions, which improved the presentation of this manuscript.

\section{References}

[1] F. E. Browder and W. V. Petryshyn, Construction of fixed points of nonlinear mappings in Hilbert space, Journal of Mathematical Analysis and Applications 20 (1967), no. 2, 197-228.

[2] C. Byrne, A unified treatment of some iterative algorithms in signal processing and image reconstruction, Inverse Problems 20 (2004), no. 1, 103-120.

[3] A. Genel and J. Lindenstrass, An example concerning fixed points, Israel Journal of Mathematics 22 (1975), no. 1, 81-86.

[4] B. Halpern, Fixed points of nonexpanding maps, Bulletin of the American Mathematical Society 73 (1967), 957-961.

[5] P. L. Lions, Approximation de points fixes de contractions, Comptes Rendus de l'Académie des Sciences. Série I. Mathématique 284 (1977), no. 21, A1357-A1359.

[6] C. I. Podilchuk and R. J. Mammone, Image recovery by convex projections using a least-squares constraint, Journal of the Optical Society of America 7 (1990), 517-521.

[7] S. Reich, Weak convergence theorems for nonexpansive mappings in Banach spaces, Journal of Mathematical Analysis and Applications 67 (1979), no. 2, 274-276.

[8] __ Some problems and results in fixed point theory, Topological Methods in Nonlinear Functional Analysis (Toronto, Ont., 1982), Contemp. Math., vol. 21, American Mathematical Society, Rhode Island, 1983, pp. 179-187.

[9] T. Suzuki, Strong convergence of Krasnoselskii and Mann's type sequences for one-parameter nonexpansive semigroups without Bochner integrals, Journal of Mathematical Analysis and Applications 305 (2005), no. 1, 227-239.

[10] R. Wittmann, Approximation of fixed points of nonexpansive mappings, Archiv der Mathematik 58 (1992), no. 5, 486-491.

[11] $\mathrm{H} . \mathrm{K} . \mathrm{Xu}$, Iterative algorithms for nonlinear operators, Journal of the London Mathematical Society. Second Series 66 (2002), no. 1, 240-256. 


\section{Strong convergence and control condition}

[12] _ An iterative approach to quadratic optimization, Journal of Optimization Theory and Applications 116 (2003), no. 3, 659-678.

[13] _ Viscosity approximation methods for nonexpansive mappings, Journal of Mathematical Analysis and Applications 298 (2004), no. 1, 279-291.

Yonghong Yao: Department of Mathematics, Tianjin Polytechnic University, Tianjin 300160, China E-mail address: yuyanrong@tjpu.edu.cn

Rudong Chen: Department of Mathematics, Tianjin Polytechnic University, Tianjin 300160, China E-mail address: chenrd@tjpu.edu.cn

Haiyun Zhou: Department of Mathematics, Shijiazhuang Mechanical Engineering College, Shijiazhuang 050003, China

E-mail address: witman66@yahoo.com.cn 


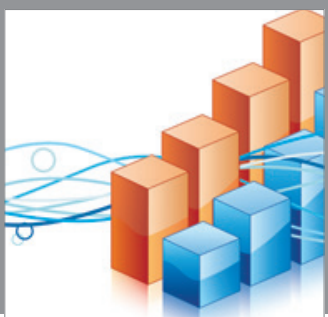

Advances in

Operations Research

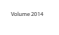

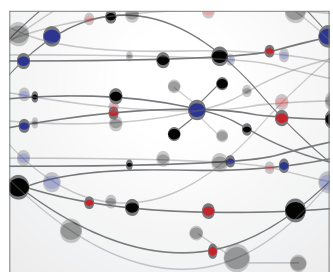

\section{The Scientific} World Journal
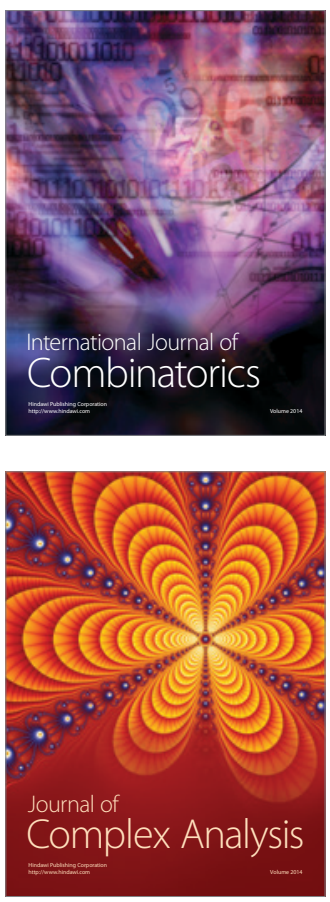

International Journal of

Mathematics and

Mathematical

Sciences
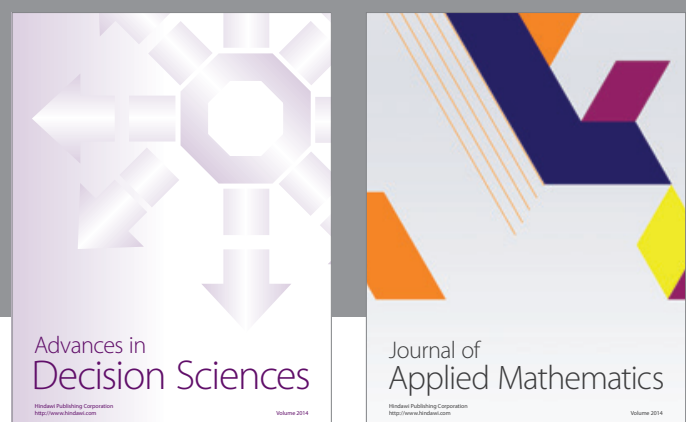

Journal of

Applied Mathematics
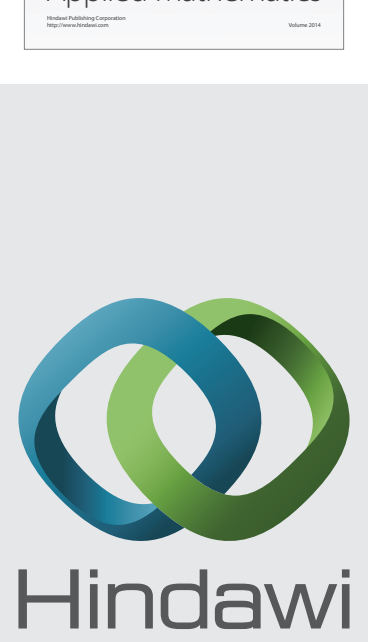

Submit your manuscripts at http://www.hindawi.com
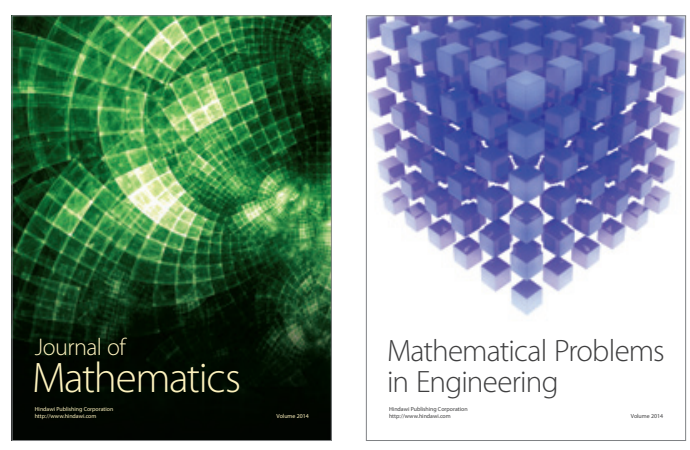

Mathematical Problems in Engineering
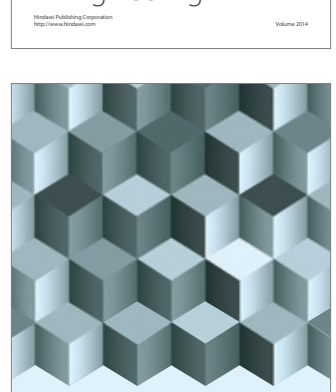

Journal of

Function Spaces
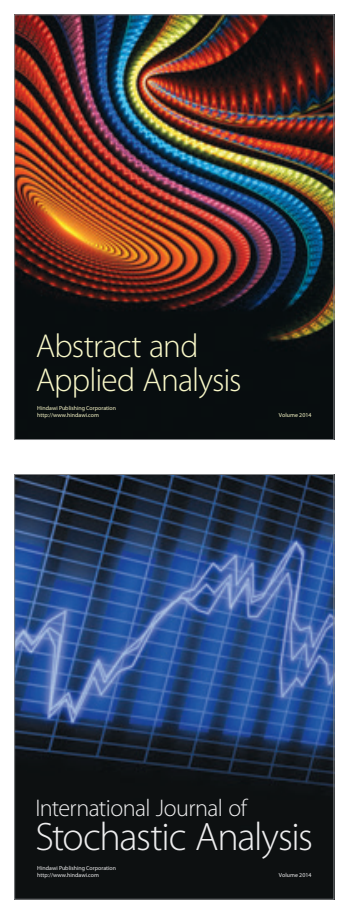

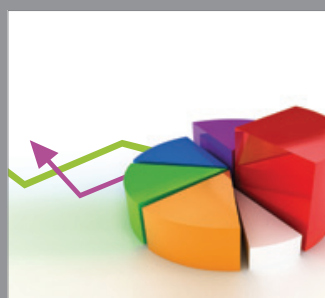

ournal of

Probability and Statistics

Promensencen
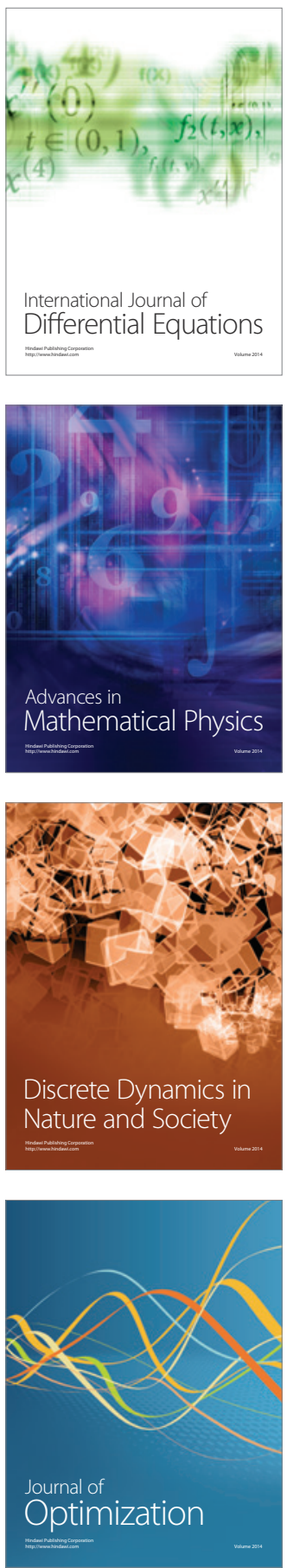